David Colton $\bullet$ Rainer Kress

\title{
Inverse Acoustic and Electromagnetic Scattering Theory
}

Third Edition

Springer 


\section{Contents}

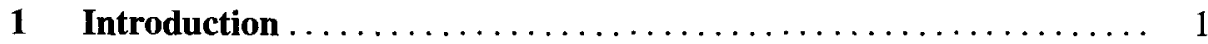

1.1 The Direct Scattering Problem $\ldots \ldots \ldots \ldots \ldots \ldots \ldots \ldots \ldots \ldots, 2$

1.2 The Inverse Scattering Problem $\ldots \ldots \ldots \ldots \ldots \ldots \ldots \ldots \ldots$

2 The Helmholtz Equation $\ldots \ldots \ldots \ldots \ldots \ldots \ldots \ldots \ldots \ldots \ldots \ldots$

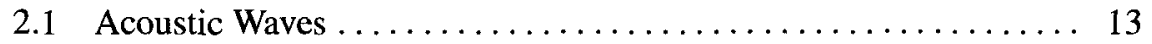

2.2 Green's Theorem and Formula $\ldots \ldots \ldots \ldots \ldots \ldots \ldots \ldots \ldots \ldots$

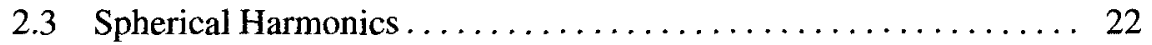

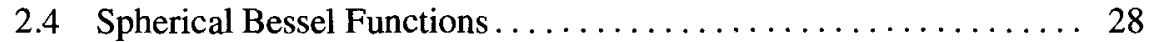

2.5 The Far Field Pattern. . . . . . . . . . . . . . . . . . 33

3 Direct Acoustic Obstacle Scattering $\ldots \ldots \ldots \ldots \ldots \ldots \ldots \ldots \ldots$

3.1 Single- and Double-Layer Potentials . . . . . . . . . . . . 40

3.2 Scattering from a Sound-Soft Obstacle . . . . . . . . . . . 48

3.3 Herglotz Wave Functions and the Far Field Operator ......... 58

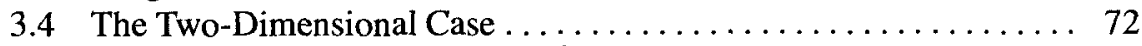

3.5 On the Numerical Solution in $\mathbb{R}^{2} \ldots \ldots \ldots \ldots \ldots \ldots \ldots \ldots \ldots$

3.6 On the Numerical Solution in $\mathbb{R}^{3} \ldots \ldots \ldots \ldots \ldots \ldots \ldots$

4 Ill-Posed Problems . . . . . . . . . . . . . . . . . . . . . . . . . . 95

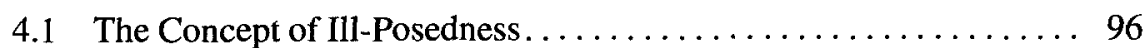

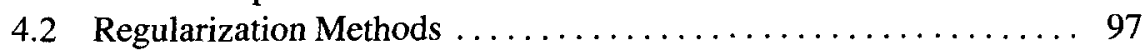

4.3 Singular Value Decomposition $\ldots \ldots \ldots \ldots \ldots \ldots \ldots \ldots \ldots 99$

4.4 Tikhonov Regularization $\ldots \ldots \ldots \ldots \ldots \ldots \ldots \ldots \ldots \ldots \ldots \ldots \ldots$

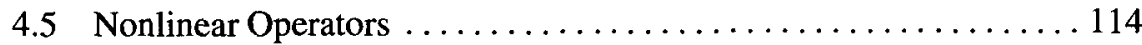

5 Inverse Acoustic Obstacle Scattering $\ldots \ldots \ldots \ldots \ldots \ldots \ldots \ldots \ldots \ldots$

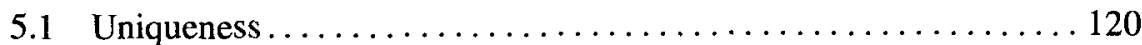

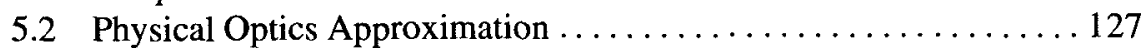

5.3 Continuity and Differentiability of the Far Field Mapping . . . . . . 129

5.4 Iterative Solution Methods $\ldots \ldots \ldots \ldots \ldots \ldots \ldots \ldots \ldots \ldots \ldots \ldots$ 


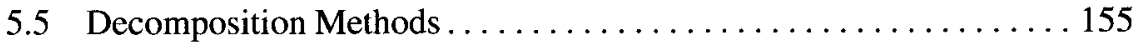

5.6 Sampling Methods $\ldots \ldots \ldots \ldots \ldots \ldots \ldots \ldots \ldots \ldots \ldots \ldots \ldots$

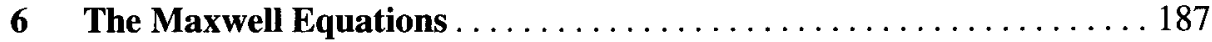

6.1 Electromagnetic Waves............................ 188

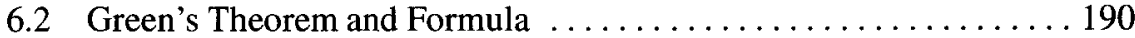

6.3 Vector Potentials . . . . . . . . . . . . . . . . . . . . . . 200

6.4 Scattering from a Perfect Conductor . . . . . . . . . . . . 209

6.5 Vector Wave Functions . . . . . . . . . . . . . . . . . 215

6.6 Herglotz Pairs and the Far Field Operator . . . . . . . . . . 224

7 Inverse Electromagnetic Obstacle Scattering $\ldots \ldots \ldots \ldots \ldots \ldots 237$

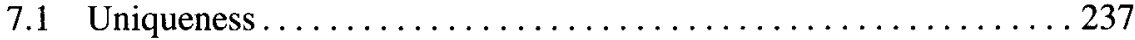

7.2 Continuity and Differentiability of the Far Field Mapping . . . . . 241

7.3 Iterative Solution Methods . . . . . . . . . . . . . . . . . . . . . . . 249

7.4 Decomposition Methods .......................... 252

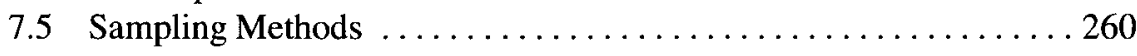

8 Acoustic Waves in an Inhomogeneous Medium ............ 265

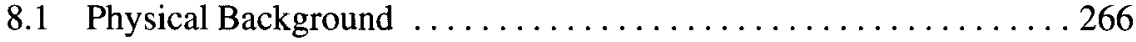

8.2 The Lippmann-Schwinger Equation ................. 268

8.3 The Unique Continuation Principle $\ldots \ldots \ldots \ldots \ldots \ldots \ldots \ldots \ldots \ldots$

8.4 The Far Field Pattern. . . . . . . . . . . . . . . . . . . . . . . . . . . 277

8.5 The Analytic Fredholm Theory .................... 286

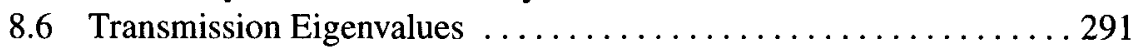

8.7 Numerical Methods................................ 299

9 Electromagnetic Waves in an Inhomogeneous Medium ........ 303

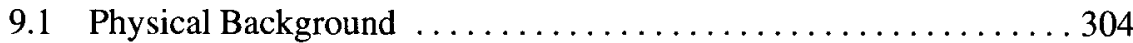

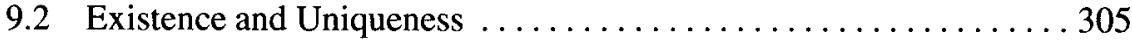

9.3 The Far Field Patterns . . . . . . . . . . . . . . . . . . . 310

9.4 The Spherically Stratified Dielectric Medium .............. 313

9.5 The Exterior Impedance Boundary Value Problem . . . . . . . . . 318

10 The Inverse Medium Problem ....................... 325

10.1 The Inverse Medium Problem for Acoustic Waves ........... 325

10.2 Uniqueness . ............................. 327

10.3 Iterative Solution Methods . . . . . . . . . . . . . . . . . . . . 333

10.4 Decomposition Methods ............................. 336

10.5 Sampling Methods and Transmission Eigenvalues ........... 346

10.6 The Inverse Medium Problem for Electromagnetic Waves . . . . . . 370

10.7 Numerical Examples . . . . . . . . . . . . . . . . . . . 382

References . . . . . . . . . . . . . . . . . . . . . . . 389

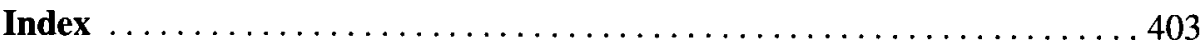

